\title{
Analysis and Evaluation of Organizational
}

\section{Change Approaches}

\author{
Yuan Liu \\ Department of Fundamental Education, Lianyungang Teacher's College \\ Lianyungang 222006, China \\ E-mail: liuyuan_0228@hotmail.com
}

\begin{abstract}
Organizational change is the trend for the further development and which been explained is the enduring quest of scholars in many disciplines. Prescriptive approach and emergent approach are two main types of models for organizational change. The 'Seven S Framework' from Peters and his colleague to show the interrelationships between different aspects of corporate strategy. Mintzberg developed his rational concept of an organisation as composed of five segments and uses his model flexibly to develop five different configurations of structure
\end{abstract}

Keywords: Organizational, Prescriptive, Emergent, Change

\section{Introduction}

"Explaining organizational change has been an enduring quest of scholars in many disciplines. Change and development process are central to such organizational phenomena as careers, group decision-making, organizational strategy formation, innovation, and interorganizational networks. Contemporary intellectual currents, exhibited in the rising interest in such topics as individual and organization life cycles, structuration theory and nonlinear systems thinking." (Poole, Van de Ven, Dooley, Holmes, 2000) In this article, a case study will be introduced to analyse and evaluated the theories of change management.

\section{Two Approaches and a Framework}

\subsection{Prescriptive and Emergent Approaches}

There are two main types of models for organisational change: prescriptive approach which works best where it is possible to move clearly from one state to another and emergent approach which is used in an unpredictable and unplanned fashion.

"Planned change (prescriptive approach) is a term first coined by Kurt Lewin to distinguish change that was consciously embarked upon and planned by an organisation, as averse to types of change that might come about by accident, by impulse or that might be forced on an organisation." (Marrow, 1969) Since planned change first mentioned by Kurt Lewin, lots of models have been developed. But they all take three-stage approach which was adapted by Edgar Schein (1964) as essential, which consists of unfreezing existing behaviour, changing behaviour, and refreezing new behaviour.

As the pioneer method of change management, weaknesses of prescriptive approach are obvious. First, if the environment is turbulent and the new destination state is unclear, company is impossible to move clearly from one state to another. Second, where major learning of new methods or substantial long-term investment is needed for the new situation, it may not even be clear when the new refrozen state has been reached. Third, it may be unrealistic if the politics within the organisation remain in flux, which means the agreement on the new refrozen state is possible. Fourth, this type of models relies on the imposition of change on the employees concerned. This may be totally inappropriate in some circumstance. (Lynch, 2005: P764)

"Emergent change consists of ongoing accommodations, adaptations, and alternations that produce fundamental change without a priori intention to do so. Emergent change occurs when people re-accomplish routines and when they deal with contingencies, breakdowns, and opportunities in everyday work." (Burnes, 1996: P291) Though there are no universal applicable rules for emergent change. But models of this type all tend to stress five features of organisations which including structures, cultures, organisational learning, managerial behaviour, and power and politics. (Burnes, 1996: P298) Especially, Pettigrew and Whipp's five factors theory provides a useful way of taking the facts from a strategic change situation and structuring them to highlight the important items. This model consists of five interrelated 
factors as follow: environment assessment, leading change, linking strategic and operational change, human resources as assets and liabilities, and coherence of purpose in the management of change. (Lynch, 2005: P768)

Compared with prescriptive approach, critiques of emergent approach is also significantly. First, it seems less a coherent approach to change and more a label for a collection of approaches critical of planned change. Second, it is criticised for its over-emphasis on the political dimension of change. Third, it is limited in terms of both the types of organisational change to which it can be applied, and how it can be applied. (Burnes, 1996: P316) In other words, increased turbulence of the environment is assumed as a justification for the emergent strategies. Fourth, there is no guarantee that the organisational learning that has already taken place will be relevant to the crisis. (Lynch, 2005: P772)

\subsection{Framework of Changing Management}

In the implementation of an organisational change, only one model can not satisfy the real conditions. (Burnes, 1996: P321) said, according to manipulating the key variables, a framework can be constructed to allow different change situations to be matched to appropriate approaches to managing change. The Figure 1 below shows the framework for the change. (Burnes, 1996: P325)

Insert Figure 1 here.

\section{3. 'Seven S Framework' and Peters' Analysis Model}

\subsection{Seven S Framework}

The 'Seven S Framework' was first launched in 1970s by Peters and his colleague to show the interrelationships between different aspects of corporate strategy. (Lynch, 2005: P792) Currently, it is used to build cohesive strategy, and to examining the organisation and what contributes to the success of an organisation. As its name shows, the framework consists of three hard elements: strategy, structure, and system; and four soft elements: style, skill, staff, and superordinate goals. Without obvious starting point, those elements are equally important and interconnected, which means altering one element may well impact on others. The simple illustrations of seven elements are listed below: (Lynch, 2005: P792)

- Strategy - the route that the company has chosen to achieve competitive success.

- Structure - the organizational structure of the company.

- Systems - the procedures that make the organization work: everything from capital budgeting to customer handling.

- $\quad$ Style - the way the company conducts its business, epitomized especially by those at the top.

- $\quad$ Staff - the pool of people, who need to be developed, challenged and encouraged.

- Skills - not just the collection of skills that the organization has but the particular combinations that help it to excel. The resource-based view was a concept invented after the framework but may at least partially capture the special nature of skills.

- Super ordinate goals. This means goals 'of a higher order' and expresses the values, concepts and vision that senior management brings to the organization.

The framework is good at capturing the importance of the links between the various elements. However, the framework says little about the how and the why of interrelationships. The model is therefore poor at explaining the logic and the methodology in developing the links between the elements. Further more the model does not highlight or emphasize other areas that have subsequently been identified as being important for corporate strategy, such as: innovation, knowledge, customer-driven service, and quality. (Lynch, 2005: P793)

\subsection{Peters' Analysis Model}

The way in which 'successful' companies handle change has been a focus of interest for a number of researchers in recent years. According to Peters' further study after 'Seven S Framework', 'success' was defined as a mixture of organization's growth and financial return together with a reputation for continuous innovation in response to changing market situations. It was not meant to imply perfection. This model focused attention on the following characteristics of business organizations: structure, strategy, systems, management style, skills, people, and shared values. (Cole, 2004: P210)

- Operate on loose-tight principles. The best companies were both tightly controlled from the centre and yet, at the same time, encourage entrepreneurship.

- Incline towards taking action. There may be analysis, but there is always a bias towards practical and fast solutions where possible.

- Close to the customer. The best companies offered customers quality, reliability and service. 
- Innovation autonomy. Responsibility is moved to individuals, who are encouraged to be as innovative as possible.

- Simplicity of organisational form. Organisation structures work better when they are clear and simple and have well-defined lines of authority and responsibility. Matrix management structures were more able to combine quickly into effective teams, task forces and project groups.

- The importance of the people resource, not just as an abstract concept but as individuals to be respected. The better companies not only made tough demands on employees but also treated them as individuals to be trained, developed and given new and interesting challenges.

- Clarity regarding the organisation's values and mission. In the best companies, many employees were clear both about the company's values and about why such values had been chosen. Better companies made a significant attempt to communicate debate and seek to inspire all within the organisation.

- Stick to the knitting. Organisations may diversify into other related areas but the companies that do best are the ones that concentrate on their core skills. Companies should not move into unrelated areas.

- Excellent companies have flexible organisation structures. This flexibility enables them to respond quickly to changes in the environment.

- Excellent companies have quite distinctive cultures. The company culture integrates the organisation's desire to meet its defined mission and objectives with two other important areas: serving customers and providing satisfying work for its employees.

- Successful strategy emerges through purposeful, but essentially unpredictable, evolution. Excellent companies are learning organisations that adapt their strategy as the environment changes through experimentation, challenge and permitting failure. (Lynch, 2005: P794)

\section{Mintzberg's Model}

Mintzberg (1983) developed his rational concept of an organisation as composed of five segments, summarised as follows: A 'strategic apex' comprising the chief executive and directors; then, proceeding down the operational line, a 'middle line' of operational management, followed by the 'operating core' of those directly involved in supplying the firm's goods and services; on either side of the operational line (traditionally called 'the line' in classical thinking) are (i) the 'techno-structure' comprising functional specialists and advisors, and (ii) the 'support staff'. Who provide corporate services (and who in classical terms would be seen as 'staff' employees). (Cole, 2004: P185)

Mintzberg uses his model flexibly to develop five different configurations of structure. His synthesis of the research on organizations produces a set of five clusters, or configurations, that provide the focal points for the study of organizations. These configurations reduce the separate influences of key organizational features into manageable concepts that can be used in the study of organizations. In Mintzberg's own words 'In each structural configuration, a different one of the coordinating mechanisms is dominant, a different part of the organization plays the most important role, and a different type of decentralization is used.' The five configurations are as follows (Cole, 2004: P186):

- $\quad$ Simple structure (basically no structure)

- Machine Bureaucracy (dominated by technical/specialist priorities)

- $\quad$ Professional Bureaucracy (dominated by skill of core staff)

- Divisionalised Form (dominated by products/outputs)

- $\quad$ Adhocracy (shared dominance of core staff and support services)

\section{Case Study}

\subsection{Background}

GK Printers Limited is a small, family-run printing business. It was established just after the Second World War by the present Managing Director's father. The company was originally a jobbing printers; which is to say they would print anything. 'No job too small' might well have been their motto, although in fact, the mainstay of their business was producing stationery, business cards and publicity brochures for local companies.

This work was moderately profitable and provided a reasonable living for the owners and their workforce, some 20 people. By the beginning of the 1980s, however, this situation was beginning to change. Firstly, the recession at this time has a strong negative effect on their traditional customer base, and orders began to fall off dramatically. Secondly, the advent of newer, computerised printing techniques, which GK had not adopted, meant that rivals could offer a quicker, cheaper and often better-quality service. Thirdly, the advent of a small printing bureaux (such as Prontaprint), often situated in prime city centre locations, and portraying an up-to-date image, further eroded GK's business. Lastly, it was clear that many of their customers were no longer going to a printer directly. Instead, in the image-conscious 1980s, they were putting their work out to graphic designers who, having finalised the design, would then subcontract out the 
printing. In such a situation, there was no guarantee that the work from their traditional customers would eventually end up with them, it depended upon the preference of the particular graphic designers concerned. All these factors combined to threaten the financial viability of GK and, for the first time ever, the company lost money. The loss was only small $(£ 20,000)$, but it came as a major shock to a company that has grown used to making a reasonable, if not spectacular, profit. The result of this was that the managing director and the company's Printing Manager, along with other members of the owning family, formed a 'crisis committee' to review the future of the business. (Burnes, 1996: P383)

From 1980 to mid-1990s, GK experienced four times individual changes. At first time, GK invited a business studies student from polytechnic to develop a strategy which includes replacing old printing machines with newer, upgrading the company's image, and developing customer base and start providing a graphic design capability. At second time, to improve customer service, manager team of GK agreed a number of key objectives on changing their systems and developed their computerised business system later on. At third time, during GK accelerating its pace of change which focuses on cutting the costs down and promoting business responding speed, another business studies student from polytechnic involved to change manager team members' attitudes and behaviours. At last time, GK launched online service after an accidental behaviour of one staff.

\subsection{Analysis of the Four Changes}

Obviously, GK's four changes introduced both planned and emergent approaches from the overall view. In here, with using Peters' analysis model, the effect of change management is analysed through different performances of GK before and after the changes.

- As a small company, GK is operated on loose-tight principle that the Managing Director reserves final power while other mid-managers receive lots of executive power.

- During the second changing, the implication of computerised business system was delayed nearly two year. The loss can be seen from the benefits brought from the application of computerised business system later on.

- In this case, the Managing Director of GK is very careful to the customer service. After each changing the improvements of customer service are significant.

- In the second changing, the introduction of computerised business system was purposed by the Printing Manager. Although the purpose was delayed, the Managing Director never ignored it, but kept discussing with the Printing Manager.

- With no more than 100 people and business focuses on a narrow area. GK keeps a simple divisionalised organisational form from 1980 to 1990 s without any difficulties.

- In the first changing, the Managing Director had expected some resistance, and later gave the print workers training for the use of new equipment instead of simply fire them off.

- At the beginning of the third changing, the meeting among managers always ended acrimoniously and no decision was taken. Fortunately, after the effort of team-builder, managers stand together once again to drive the change. Everyone is clear with their missions.

- Two times diversification of business are operated very successfully by GK. Either after providing graphic design capability in the first change or providing online service in the fourth change, GK's income is greatly enlarged.

- From the first changing period, the Managing Director set a weekly coordinating meeting mechanism which calls the manager from each department together to negotiate.

- The factor that GK acts as a learning organisation is can be seen from the fourth changing when as soon as one staff successfully handing out an electronically requirement from customer, the company decide to issue online service.

Finally, following Mintzberg's configuration model, from organisation structure point of view, the impact the configuration of the GK has on the nature of its management can be concluded as follow. First, during the first change period, GK is a simple structure which's prime coordinating supervision is direct supervision, and key part of organization is strategic apex (the Managing Director). It is the Managing Director who invited outside expert to help to survive. Second, during the third change period, the coordinating mechanism of standardisation of outputs of divisionalised configuration form makes sticking in the mud, due to the bad attitude between managers. At last, in the last change period, a key staff lead to the thinking of providing online service appears in the Managing Director's mind.

\section{Evaluation}

From the case study, it can be see that currently company tends to implement their changing management through a comprehensive way. Only one approach can not meet the company's requirement. And learning ability of an organisation becomes the crucial point of continuous and incremental change strategy, which is the most effective way to keep an organisation's competition ability under the turbulent environment. 


\section{References}

Burnes, B. (1996). Managing Change: The Emergent approach to change. Person Education Limited (2004 fourth edition). P291- P325.

Caldwell, R. (2006). Agency and Change. Raymond Caldwell.

Cobbenhangen, J. (2000). Successful Innovation. Edward Elgar, Cheltenham, UK. Northampton, MA, USA.

Cole, G.. (2004). Management Theory and Practice: Organising for Management. Thomson, (2004 Sixth edition). P210.

Fenton, E., \& Pettigrew, A. (2000). The innovating organization. SAGE Publications Ltd London.

Griffiths, K., \& Williams, R. (1998). A Learning Approach to Change. GOWER. USA.

Henry, J., \& Mayle, D. (2002). Managing Innovation and Change. The Open University, (2002,Second edition).UK.

Lynch, R. (2005) .Corporate Strategy: The Implementation Process. Person Education. Limited, (2006 fourth edition). P. 679-P805.

Macdonald, S. (2000). Information For Innovation. Oxford, UK.

Marrow, AJ. (1969). The Practical Theorist: The Life and Work of Kurt Lewin. Teachers College Press (1997 edition): New York.

Merli, M., \& Wheeler. (1995). Beyond Business Process Reengineering. John Wiley \& Sons Ltd, UK.

Mintzberg, H. (1983). Structure in Fives: Designing Effective Organisations, Prentice-Hall.

Poole, S. M., Van de Ven, A, Dooley, K., \& Holmes, M. (2000). Organizational Change And Innovation Processes. Oxford. UK.

Rouse, William, B. (1992). Strategies For Innovation. John Wiley \& Sons Ltd, UK.

Schein, E. (1964). The Mechanics of Change.W. G.. et al (eds), Interpersonal Dynamics, Dorsey Press. UK.

Tidd, J. Bessant, J., \& Pavitt, K. (2003). Management Innovation, John Wiley \& Sons Ltd, (2003,the second edition), UK.

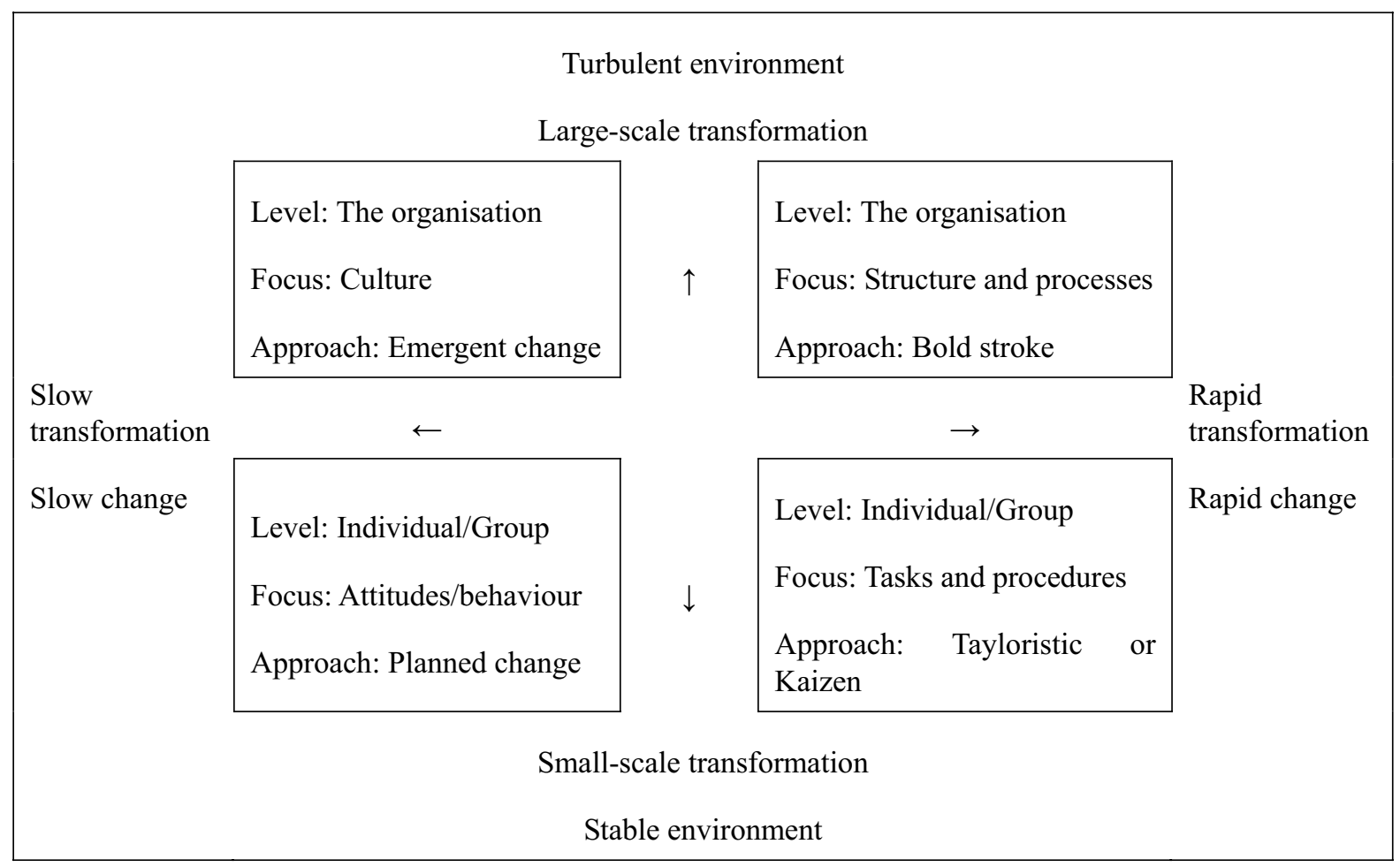

Figure 1. 